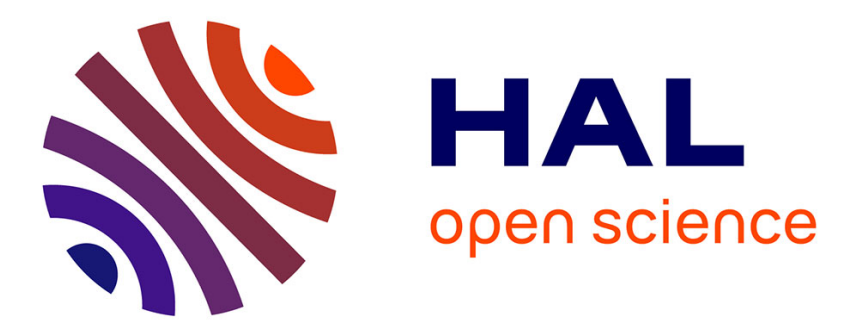

\title{
Texture analyses of chemically vapor deposited coatings in the Ti-C-N system by wide film Debye-Scherrer X-ray diffraction technique
}

S. Eroglu, B. Gallois

\section{- To cite this version:}

S. Eroglu, B. Gallois. Texture analyses of chemically vapor deposited coatings in the Ti-C-N system by wide film Debye-Scherrer X-ray diffraction technique. Journal de Physique IV Proceedings, 1993, 03 (C3), pp.C3-177-C3-182. 10.1051/jp4:1993322 . jpa-00251379

\section{HAL Id: jpa-00251379 https://hal.science/jpa-00251379}

Submitted on 1 Jan 1993

HAL is a multi-disciplinary open access archive for the deposit and dissemination of scientific research documents, whether they are published or not. The documents may come from teaching and research institutions in France or abroad, or from public or private research centers.
L'archive ouverte pluridisciplinaire HAL, est destinée au dépôt et à la diffusion de documents scientifiques de niveau recherche, publiés ou non, émanant des établissements d'enseignement et de recherche français ou étrangers, des laboratoires publics ou privés. 


\title{
Texture analyses of chemically vapor deposited coatings in the Ti-C-N system by wide film Debye-Scherrer X-ray diffraction technique
}

\author{
S. EROGLU ${ }^{(1)}$ and B. GALLOIS
}

Department of Materials Science and Engineering, Stevens Institute of Technology, Hoboken, NJ 07030, U.S.A.

\begin{abstract}
Texture analyses were performed on the chemically vapor deposited monolithic TiN, TiC, TiC $\mathrm{N}_{y}$ coatings and graded TiN/TiC coatings by wide film Debye-Scherrer $x$-ray diffraction technique. The preferred orientations of the coatings were investigated as a function of coating thickness and input gas composition. The growth of TiN and TiC coatings was initiated as randomly oriented crystallites which subsequently grew into large columnar grains with a <110> preferred orientation. The textures of TiC coatings with the same thickness changed from the $\langle 110\rangle$ orientation to the $<100\rangle$ orientation with decreasing hydrogen concentration in the gas phase. TiC $\mathrm{N}_{\mathrm{y}}$ coatings exhibited a preferred orientation of $\left\langle 111>\right.$ up to the $\mathrm{CH}_{4} / \mathrm{CH}_{4}+\mathrm{N}_{2}$ ratio of 0.14 above which a strong <100> texture developed. The texture analyses on the graded TiN/TiC coatings showed that the Tic top layers were oriented in a $\langle 100\rangle$ direction perpendicular to the sample surface.
\end{abstract}

\section{Introduction}

Coatings synthesized by chemical vapor deposition technique often exhibit a high degree of texture or preferred orientation. Preferred orientation affects coating properties such as hardness which, in turn, can influence the performance of the coatings [1]. For example, Tic coatings with a $\langle 100\rangle$ texture exhibited better cutting performance than those with a $\langle 111\rangle$ orientation [2].

studies of textures in hard coatings deposited by chemical vapor deposition (CVD) technique [3-5] indicate that low index-planes such as (200), (220) and (111) tend to grow parallel to the substrate's surface. It is known that texture depends on the growth parameters such as deposition temperature, gas composition and substrate. There is, however, a lack of published information on the relationship between preferred orientation and CVD process parameters. The purpose of the present investigation was to systematically study the effect of deposition parameters on textures in the monolithic $\mathrm{TiN}, \mathrm{TiC}, \mathrm{Ti}_{\mathrm{x}} \mathrm{N}_{\mathrm{y}}$ and graded TiN/TiC coatings by wide film Debye-Scherrer X-ray diffraction technique.

\section{Experimental Details}

2.1. Chemical Vapor Deposition

The depositions were carried out on polycrystalline graphite substrates in a computer-controlled hot-wall chemical vapor deposition reactor. The experimental conditions for chemical vapor deposition of $T i N$ 
are described elsewhere [6]. AlI the deposition experiments were conducted at a total pressure of $10.7 \mathrm{kPa}$ ( 80 torr) and a total flow rate of $670 \mathrm{sccm}$. In order to study the effect of hydrogen concentration on texture in TiC coatings grown at $1425 \mathrm{~K}$, the hydrogen flow rate was varied from $100 \mathrm{sccm}$ to $600 \mathrm{sccm}$ at constant $\mathrm{CH}_{4}(50 \mathrm{sccm})$ and $\mathrm{TiCl}_{4}(20$ sccm) flow rates. The total flow rate was maintained constant with argon. Details of the chemical vapor deposition of TiC and the properties of the graphite substrates are given in Ref. [7].

$\mathrm{Ti}(\mathrm{C}, \mathrm{N})$ monolithic coatings with $\mathrm{C} / \mathrm{C}+\mathrm{N}$ ratio in the range $0-1$ were grown at $1400 \mathrm{~K}$ by varying the $\mathrm{CH}_{4} / \mathrm{CH}_{4}+\mathrm{N}_{2}$ ratio $\left(\mathrm{X}_{\mathrm{CH} 4}\right)$ in the input gas composition. Continously graded TiN/TiC coatings with parabolic, linear and exponentional composition profiles were also synthesized at $1400 \mathrm{~K}$ by using the methodologies described elsewhere [8].

\subsection{Texture Analyses}

Texture analyses were performed on a Read thin film camera of radius $5.0 \mathrm{~cm}$. This camera is essentially a Debye-Scherrer X-ray diffraction camera equipped with a wide photographic film $(18 \mathrm{~cm} \times 13 \mathrm{~cm})$. Nickelfiltered copper radiation was used. The sample was held stationary at a given angle of incidence (generally $25^{\circ}$ ). The results obtained were checked and found to be in good agreement with those obtained by conventional $\mathrm{x}$-ray diffraction technique [7].

The wide film Debye-schrerrer $x$-ray diffraction technique is extremely useful for quickly obtaining an overview of the structure of the coatings such as texture. In this technique, the reflections from the planes parallel and inclined to the surface of the sample can be detected simultaneously, whereas in the case of the conventional diffractometer the reflections observed are from the planes parallel to the surface. It is especially well suited for studying coatings since a fixed small angle to the incident $x$-ray beam can be used to increase the path length of the $x$-rays through the coating [9].

\section{Results and Discussion \\ 3.1. Effect of Coating Thickness}

Fig. 1 shows $x$-ray diffraction patterns of the TiN coatings deposited at $1300 \mathrm{~K}$. The degree of preferred orientation in the coatings is inversely proportional to the length of the diffraction rings recorded on a photographic film. If certain (hkl) planes are oriented preferentially parallel to the substrate's surface, the (hkl) diffraction ring will exhibit a much higher intensity at its central portion in the form of a short arc, the length of which can be used as a qualitative indication of the sharpness of the preferred orientation in the coating. As can be seen in Fig. 1 , the thinner coating (thickness $1.5 \mu \mathrm{m}$ ) exhibits continous diffraction rings while the coating with a thicknesses of 12 $\mu \mathrm{m}$ has discontinous rings with non-uniform intensities. With increasing coating thickness, the intensity of the (220) reflection increases near the equatorial plane of the diffraction pattern whereas the intensities of the (111), (200) and (311) reflections decrease. The thinner coating has a near random structure and thicker coatings have a <110> fiber texture or preferred orientation perpendicular to the plane of the coating. The sharpness of $\langle 110\rangle$ orientation also increases with the coating thickness. The same trend was observed for the Tic coatings.

Texture studies indicate that the coatings at the beginning of the growth tend to have a nearly random structure, and that a $\langle 110\rangle$ fiber texture develops as growth proceeds. This behavior can be explained by evolutionary selection theory [10]. The coatings are comprised of fine grains near the interface between the coating and the substrate. With increasing coating thickness, certain individual grains become greater in diameter, screening and suppressing less favorable grains. The 
surface morphology of the coatings grown at $1300 \mathrm{~K}$ are shown in Fig. 2 as a function of thickness. The coating with a thickness of $1.5 \mu \mathrm{m}$ has an acicular structure with a submicrometer grain size whereas the $12 \mu \mathrm{m}-$ thick coating exhibits larger grains with a size of the order of $3 \mu \mathrm{m}$.
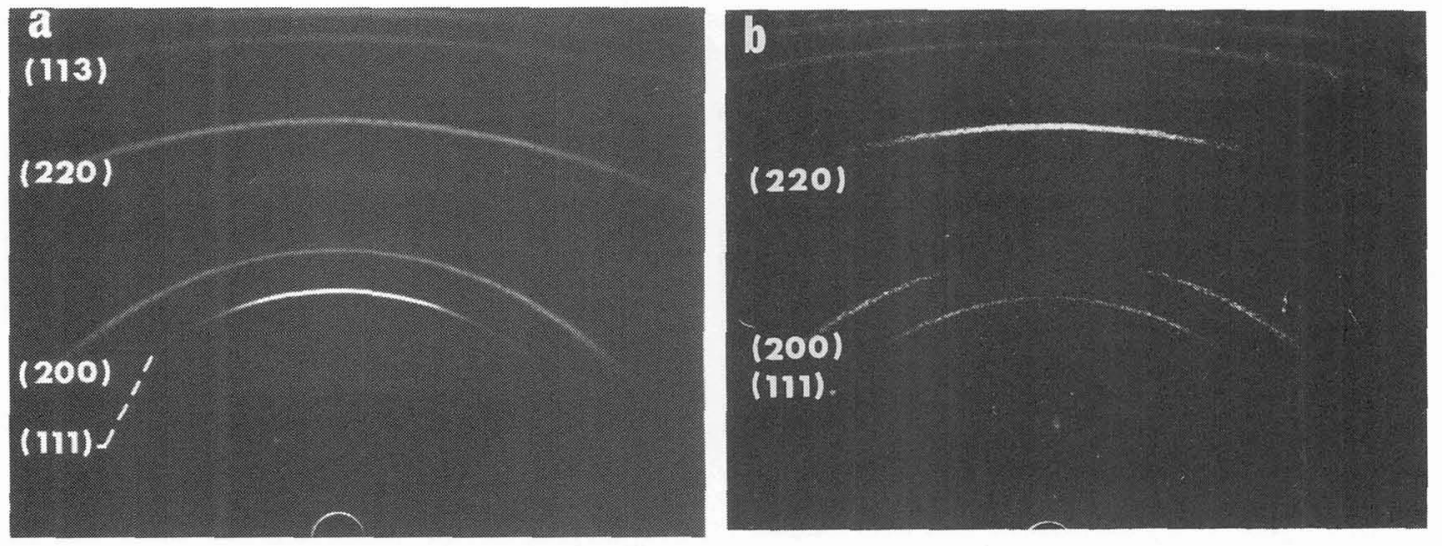

Fig. 1- X-ray diffraction patterns of the TiN coatings deposited at 1300 $K$ as a function of thickness: (a) $1.5 \mu \mathrm{m}$ and (b) $12 \mu \mathrm{m}$. The (101) and (004) reflections originated from the graphite substrate.
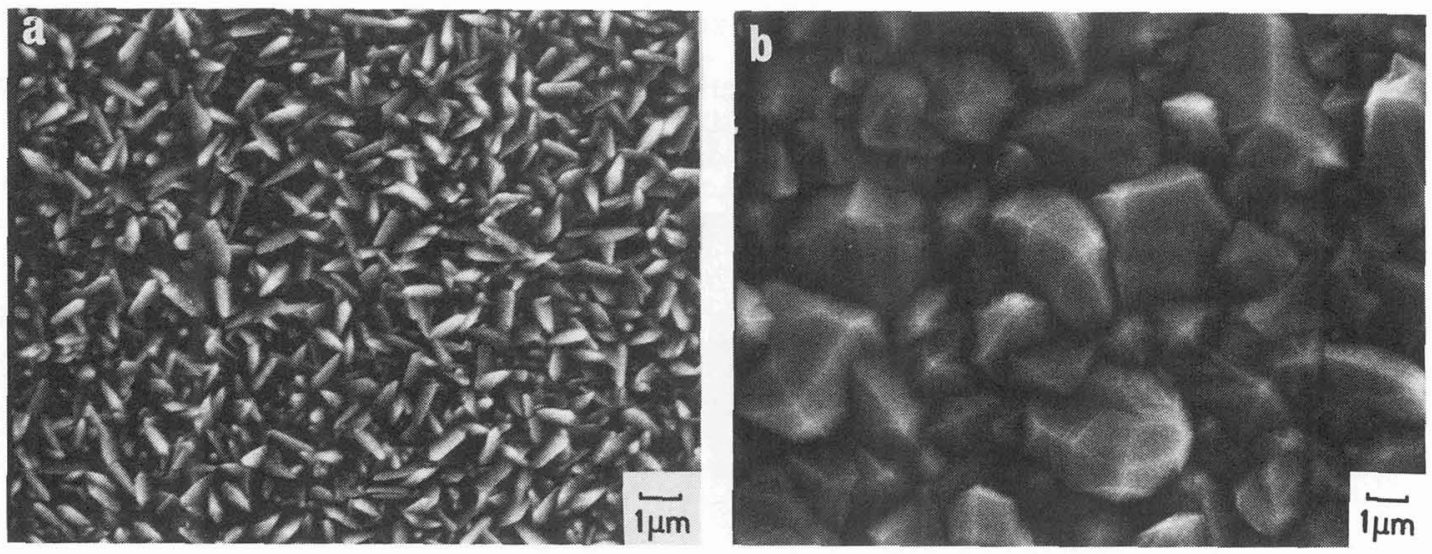

Fig. 2- Surface morphology of the TiN coatings with thicknesses of (a) 1.5 $\mu \mathrm{m}$ and (b) $12 \mu \mathrm{m}$ grown at $1300 \mathrm{~K}$.

From these observations, it can be concluded that there is a competition between differently oriented grains. As growth proceeds, more and more grains are overgrown by adjacent crystals and the number of grains extending to the surface decreases progressively. Only those crystals with a <110> growth orientation perpendicular or nearly perpendicular to the substrate surface survives, whereas grains with other orientations are gradually buried.

\subsection{Effect of Input Gas Composition}

Texture in Tic coatings is greatly influenced by the hydrogen flow rate in the range $600-100 \mathrm{sccm}$. The growth rate of the TiC coatings is not affected, however, by the hydrogen concentration in the input gas 
composition [7]. The thickness of the coatings was measured to be around $8 \mu \mathrm{m}$. The sharpness of the $\langle 110\rangle$ preferred orientation observed in the TiC coatings decrease with decreasing hydrogen flow rate up to $200 \mathrm{sccm}$ at which point a slight $\langle 311\rangle$ orientation is observed. Above that, the coating has a high <100> preferred orientation. Fig. 3 shows the X-ray diffraction patterns of Tic coatings grown at hydrogen flow rates of 100 sccm and $400 \mathrm{sccm}$.
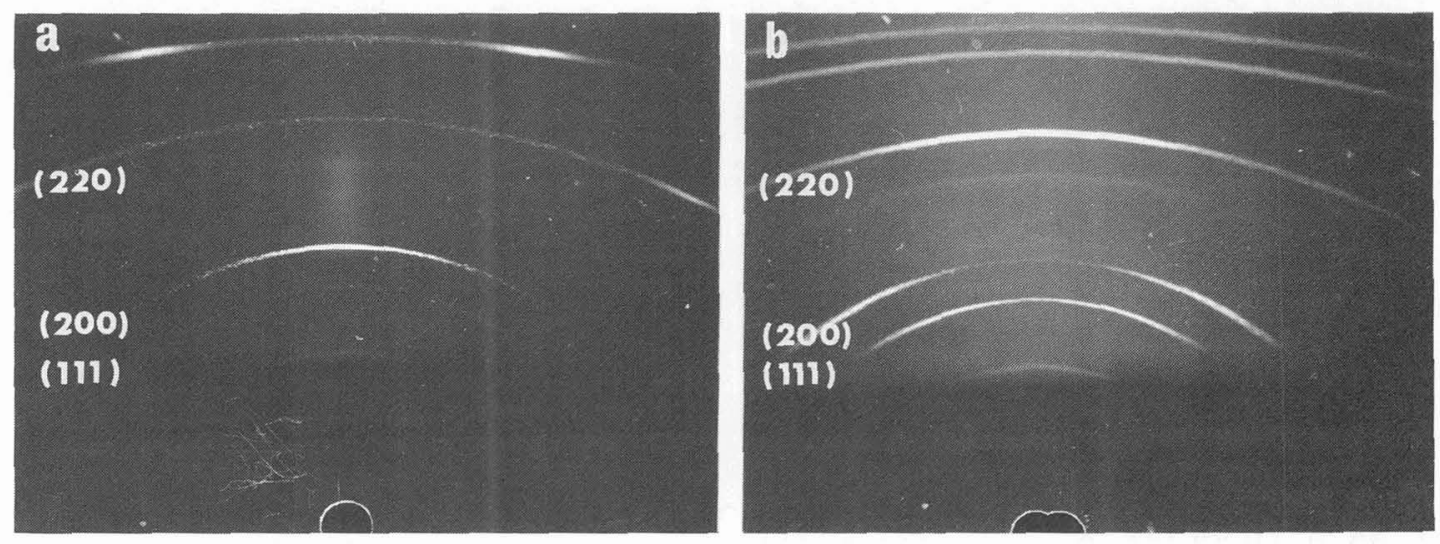

Fig. 3- X-ray diffraction patterns of TiC coatings grown at hydrogen flow rates of (a) $100 \mathrm{sccm}$ and (b) $400 \mathrm{sccm}$.

The texture studies on monolithic $\mathrm{TiC}_{x} \mathrm{~N}_{y}$ coatings reveal that as the $\mathrm{CH}_{4} / \mathrm{CH}_{4}+\mathrm{N}_{2}$ ratio in the gas phase increases, the preferred orientation observed in the $\langle 111\rangle$ direction at low methane concentrations changes to the $\langle 100\rangle$ direction. The transition ratio $\left(\mathrm{X}_{\mathrm{CH}}\right)$ was determined to be 0.14. The sharpness of the $\langle 100\rangle$ orientation increases with increasing $\mathrm{CH}_{4} / \mathrm{CH}_{4}+\mathrm{N}_{2}$ ratio. Fig. 4 shows some of the diffraction patterns of the
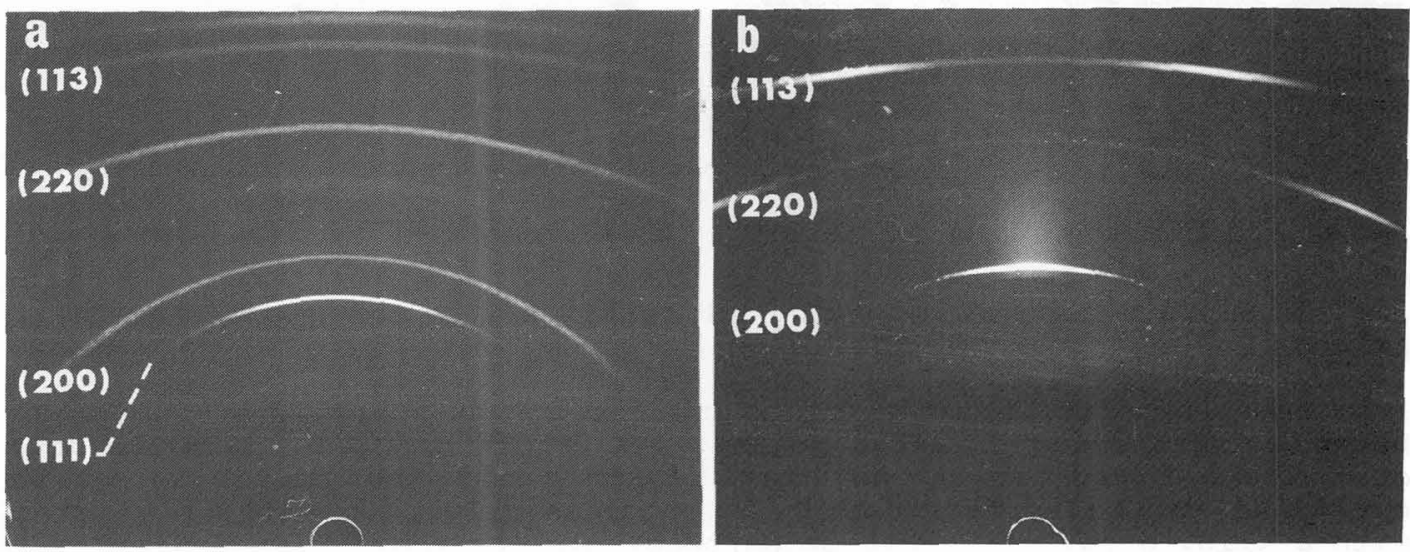

Fig. 4- X-ray diffraction patterns of the coatings grown at $\mathrm{CH}_{4} / \mathrm{CH}_{4}+\mathrm{N}_{2}$ ratios of (a) 0.14 and (b) 0.74 .

TiC $\mathrm{N}_{y}$ coatings. The coatings exhibit columnar grains, typical of preferrentially oriented coatings.

Surface morphologies of the graded TiN/TiC coatings consisted of uniformly distributed faceted square based pyramids as shown in Fig. 
5(a). The cross-sectional view of the parabolically graded coating reveals that the growth starts with fine grains near the interface between the TiN layer and the substrate and develops into narrow columnar ones on which small grains are grown [Fig. 5(b)]. Above this zone, large columnar grains are observed. Texture analyses on the graded TiN/TiC coatings showed that the Tic top layers have a fiber texture of <100> orientation (Fig. 6). This texture was expected from the deposits with surface morphologies characterized by square-based pyramids with facets consisting of (111) planes.

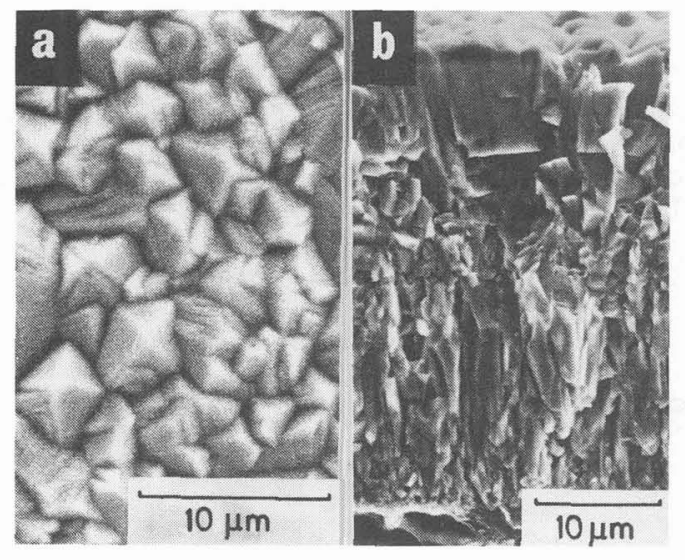

Fig. 5- Scanning electron micrographs of the graded coating with a parabolic composition profile:(a) Surface morphology and (b) crosssectional view.

The textures in the coatings are greatly influenced by input gas composition, as the studies indicate. The source of the development of the textures might be related to the preferential attachment of gaseous species on crystal planes, thus poisoning or promoting the growth of certain crystallographic planes. It would be worthwhile to identify the gaseous species on the substrate's surface. Correlations of the adsorbed species with texture could lead to the understanding of the development of preferred orientation. Since preferred orientation is accompanied by columnar growth and since columnar grains are structurally weak, the determination of process conditions which prevent columnar growth would be invaluable.

\section{Conclusions}

Wide-film Debye-Scherrer X-ray diffraction camera technique was employed for the texture analyses of the chemically vapor deposited coatings in the Ti-C-N system. The growth of the TiC and TiN coatings was initiated as randomly oriented grains which then grew in a columnar mode. The grains with a <110> orientation suppressed the growth of grains of other orientations, as the growth proceeded. The Tic coatings tended to have a $\langle 100\rangle$ texture as the hydrogen concentration decreased. $\mathrm{TiC}_{\mathrm{x}} \mathrm{N}_{\mathrm{y}}$ coatings grown at low $\mathrm{CH}_{4}$ concentration exhibited a $\langle 111\rangle$ texture and a strong $\langle 100\rangle$ texture developed in these coatings as the $\mathrm{CH}_{4}$ concentration increased. The $\langle 100\rangle$ texture was also observed in the top TiC layers of continuously graded TiN/TiC coatings. 


\section{Acknowledgements}

The authors gratefully acknowledge the partial support of the Army Research office, Division of Materials Science, under contract DAAG29-85K-0124, and the New Jersey Advanced Technology Center for Surface Engineered Materials. S. Eroglu was partially supported by the Ministry of Education of the Republic of Turkey.

\section{References}

[1] Sundgren J. E., and Hentzell H. T. G., J. Vac. Sci. Technol. A, 4 (1986) 2259 .

[2] Sue J. A. and Troue H. H., Surf. Coat. Technol., 33(1987) 170 .

[3] Lee C. W. and Chun J. S., in Blocher Jr. J. M., Vuillard G. E. and Wahl G. (eds.), Proc. 8th Int. Conf. Chemical Vapor Deposition, Electrochemical Society, Pennington, NJ, 1981, p.563.

[4] Kim M. S. and Chun J. S., Thin Solid Films, 107 (1983) 129.

[5] Itoh H., Kato K. and Sugiyama K., J. Mater. Sci., $21(1986) 751$.

[6] Paik J. S., Ph. D. Thesis, Stevens Institute of Technology, Hoboken, New Jersey, 1991.

[7] Eroglu S., Ph. D. Thesis, Stevens Institute of Technology, Hoboken, New Jersey, 1991.

[8] Eroglu S. and Gallois B., Surf. Coat. Technol., 49 (1991) 275.

[9] Westwood W.D., Thin Solid Films, 15(1973) 16.

[10]van der Drift A., Phillips Research reports, $22(1967) 267$. 